\title{
Energy system impacts from heat and transport electrification
}

Pranab J. Baruah MEng, MBA, PhD, LEED-AP

Researcher (energy), Environmental Change Institute, University of Oxford, UK

Nicholas Eyre MA, DPhil, FEl, HonFSE

Energy Programme Leader and Senior Research Fellow, Environmental

Change Institute, University of Oxford, UK

Meysam Qadrdan MSc, PhD

Research Associate, Department of Electrical and Electronic Engineering, Imperial College, London, UK

Modassar Chaudry MEng, PhD

Research Associate, Institute of Energy, Cardiff University, UK

\author{
Simon Blainey MSc, PhD, FRGS, MCIHT \\ Lecturer, Faculty of Engineering and the Environment, University of \\ Southampton, UK \\ Jim W. Hall MA, PhD, CEng, FREng, FICE \\ Director and Professor, Environmental Change Institute, University of \\ Oxford, UK \\ Nicholas Jenkins PhD, FREng, FIEEE, FIET \\ Director and Professor, Institute of Energy, Cardiff University, UK \\ Martino Tran MSc, DPhil \\ Senior Research Fellow, Environmental Change Institute, University of \\ Oxford, UK
}

Electrifying the energy system and powering it by low carbon electricity is one of the key decarbonisation pathways of the energy system. This study examines annual electricity and gas consumption in a high electrification scenario in Great Britain (GB) and the implications for electricity generation and transmission infrastructure using a suite of softlinked models. High electrification of heating and transport services, which are two major fossil fuel consumers in GB, increases annual electricity consumption and peak electricity load by $35 \%$ and $93 \%$, respectively, by 2050 while reducing overall annual energy consumption compared to a reference case. Meeting this high electricity consumption with a supply strategy that is dependent on offshore wind could more than double the supply-side investments required compared to a reference case, if demand-side measures are not available. High electrification would also impact existing gas and oil energy infrastructure by reducing consumption of these fuels. It was found that uncertainties in socio-economic growth can amplify these implications and therefore need serious consideration by analysts and policymakers involved in designing energy transition strategies. A case study and discussion demonstrate that smart-grid aided demand-side management has the potential to minimise electricity peak load and infrastructure requirements from high electrification.

\section{Notation}

$C_{t}$

DemandResponse

E

$E D$

EDCBehavMngtChange

EDIncFuelSwitch

EDRedFuelSwitch

EDRedOnsiteGenUse

EDRedReuse average cost of travel in year $t$, given by the cost per litre of fuel

aggregate demand response (other than V2G)

energy end-use types

energy consumption

change in energy consumption from conservation/management measures increase in energy consumption from technology (fuel) switching (e.g. gas boiler to gas CHP)

reduction in energy consumption from technology (fuel) switching (e.g. gas boiler to heat pumps) energy demand met with onsite energy production (e.g. solar PV, CHP) energy demand met with energy recovery and reuse
EDSocioEconDriver

ElecHeatPL

ElecTransportPL

EDREfficiency

F

$I_{\text {it }}$

Ref_PL

$P_{i t}$

$R$

$S$ energy consumption driven by socioeconomic growth with base year technology mix

change in peak electricity load from electrification of heat

change in peak electricity load from transport electrification (G2V and V2G)

reduction in energy consumption from energy efficiency

fuel type in end-use $E$ (in fuel switching) gross value added per capita in zone $i$ in year $t$

national reference peak electricity load with base year technology mix if any

population in zone $i$ in year $t$

GB government official regions

economic sub-sectors or dwelling types 


$\begin{array}{ll}S_{i t} & \begin{array}{l}\text { estimated mean speed of road traffic } \\ \text { in zone } i \text { in year } t\end{array} \\ V k m & \text { total road vehicle km in zone } i \text { in year } t \\ Z & \text { total infrastructure, operational and } \\ & \text { unserved energy cost } \\ & \text { discount rate }(3 \% \text { for network expan- } \\ & \text { sion, } 10 \% \text { for all other investments) } \\ & \text { simulation year } \\ t & \text { elasticity of demand with respect to } \\ & \text { average cost of travel } \\ \eta_{c} & \text { elasticity of demand with respect to } \\ & \text { gross value added per capita } \\ \eta_{I} & \text { elasticity of demand with respect to } \\ & \text { population } \\ \eta_{p} & \text { elasticity of demand with respect to } \\ & \text { speed of road traffic }\end{array}$

\section{Introduction}

Under the Climate Change Act 2008, the UK has a legally binding commitment to an $80 \%$ reduction of Kyoto Protocol greenhouse gases by 2050 relative to its 1990 level. The Committee on Climate Change (CCC), the government's independent advisory body on the Climate Change Act 2008, suggests 'domestic actions' for a $60 \%$ emissions reduction by 2035 with deep cuts through the 2020 s onwards. Decarbonising the energy system lies at the heart of this effort, given the high emissions from fossil fuel energy sources and cross-sectoral impacts. Electrifying the energy system using low carbon electricity is seen as one of the key pathways for its potential system efficiency benefits along with reductions in general pollutants and greenhouse gas emissions. Aided by prerequisites such as a smart grid and ubiquitous smart meters, electrification has the potential to provide significant peak load management capabilities from electric vehicles and local heat storage. It can also provide better demand forecasting, remote control of distributed loads for demand management and dynamic demand-supply balancing opportunities in a future European super-grid.

In the UK, a high electrification pathway would have to involve electrifying two fossil fuel-dominant major energy service categories - heating end uses and transport services currently responsible for $49 \%$ ( $78 \%$ excluding transport) and $37 \%$ of annual energy consumption, respectively. Heating end uses are responsible for about a third of UK greenhouse gas emissions (DECC, 2013a). In 2010, 70\% of heating and 97\% of transport energy consumption was met by natural gas and oil, respectively (ECUK, 2013).

Extensive work has been done on assessing the potential of electric vehicles for grid balancing and integration of renewables (Richardson, 2013). Infrastructure investment impacts have also been assessed including distribution network costs from different charging regimes (Fernandez et al., 2011). Long-term energy system transition scenario studies both for the UK and EU have also considered electrification of heating and transport at various levels (CCC, 2013; EC, 2011; Eurelectric, 2011; RAE, 2010; Skea et al., 2011). The UK context has been assessed in detail including electric vehicle loads using drive cycle data to analyse electrical energy usage and storage, and the potential for vehicle and residential load integration (Dyke et al., 2010). Further work also assesses the impacts of the high uptake of both electric vehicles and heat pumps in the UK indicating increasing electricity peak load up to two to three times under a business as usual scenario (Pudjianto et al., 2013).

Supply-side responses have also been assessed focusing on different levels of fossil fuel imports to meet future electricity consumption (Barton et al., 2013).

The research reported in this paper builds on this literature focusing on the UK context. Both long-term consumption and supply responses to increased electrification of heat and transport were assessed in Great Britain (GB: England, Scotland and Wales) through detailed sector-wise analysis by using a suite of bespoke engineering models. In 2011, GB was responsible for $97 \%$ of the UK's energy consumption (ECUK, 2013). The analysis is focused on two major energy carriers in the GB energy system, electricity and gas. On the demand side, implications for both annual consumption and peak loads are evaluated. On the supply side, electricity supply mix and transmission level investment implications are quantified by a combined electricity and gas network expansion planning model. The impact of electrification on gas and electricity distribution networks is beyond the scope of this work.

In addition, this paper presents a novel approach to show how macro-level impacts from economic and population uncertainties can influence sectoral level energy consumption in the longer term. Most analysts and policymakers have ignored this uncertainty despite its importance in developing the business case and designing robust transition strategies for decoupling socio-economic growth from energy consumption. It is expected that the modelling approach and results presented in this study could also provide insights for other countries considering rapid electrification of heat and transport as a climate mitigation strategy.

\section{Methodology and data}

\subsection{Modelling framework}

The analysis uses explicit sector models and a system of systems framework (Figure 1) developed within the UK Infrastructure Transitions Research Consortium (see http:// www.itrc.org.uk/) for long-term integrated analysis of national 


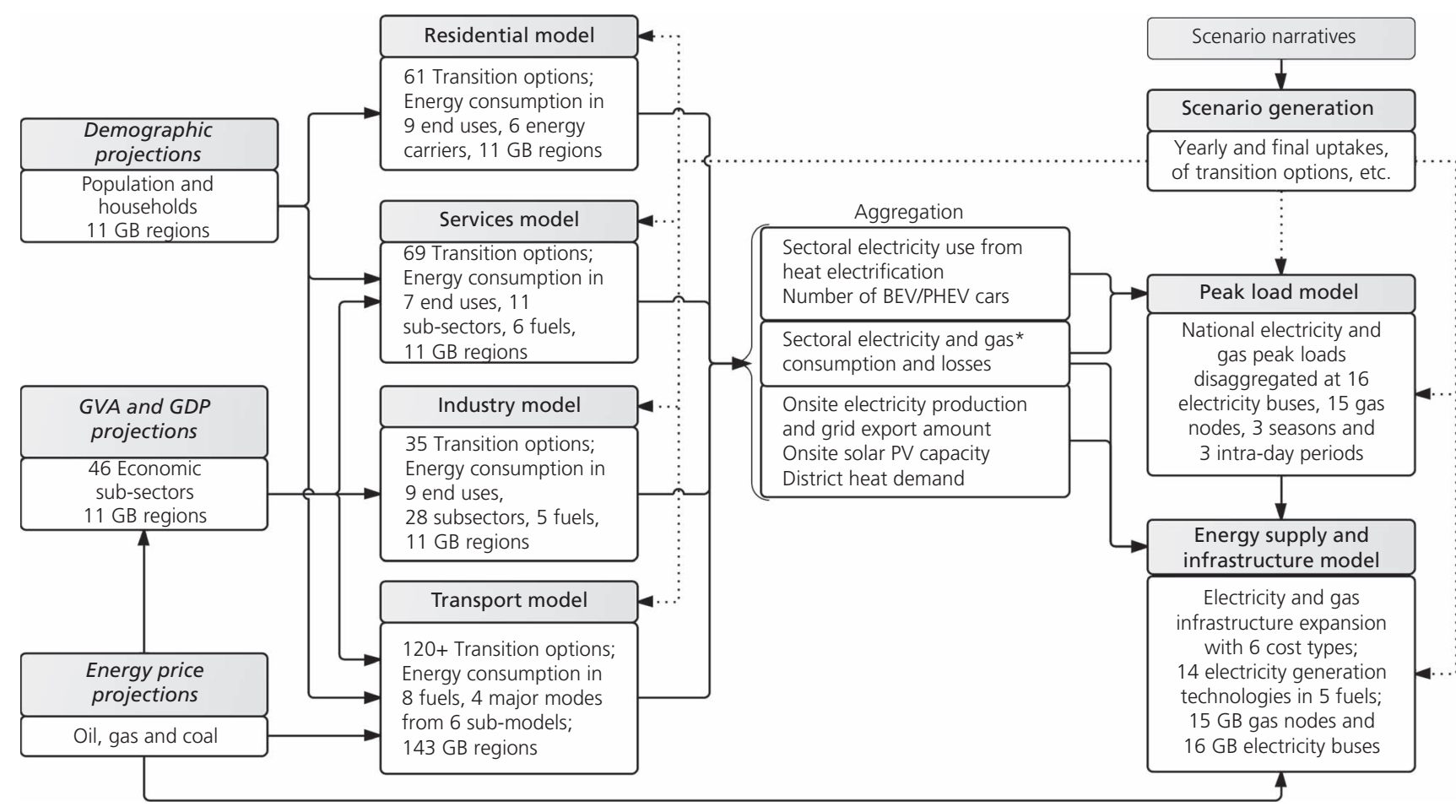

* Excludes consumption in electricity generation

Figure 1. Modelling framework with major inter-model data links

infrastructure systems (Hall et al., 2013, 2014; Tran et al., 2014). The modelling framework (Figure 1) incorporates contrasting modelling approaches, including demographic and economic factors, residential, services and industrial energy demand, and energy supply infrastructure. These different modelling approaches are integrated by

identifying and harmonising key soft-linking points across the models

- using a standardised common input dataset of major socioeconomic drivers (energy prices, regional demography, subsectoral gross value added), which are exogenous to all models

- starting with high-level policy aspirations and translating these to sector-specific narratives, objectives and required transition option portfolios (Tran et al., 2014).

Major data/parameter inter-linkages between sectoral energy consumption, peak load, and energy supply models are shown in Figure 1.

In the residential, services and industry sector energy consumption models, more than 160 options are available to simulate scenariospecific energy conservation, energy efficiency, fuel switching and onsite generation uptakes. Using an end-use accounting-simulation approach, energy consumption disaggregated by end use, sub-sector/region and fuel type is estimated. Equation 1 shows the generic logic used in the models. Each variable in the equation (except onsite generation, EDRedOnsiteGenUse) is calculated sequentially based on the estimate within the closed brackets immediately preceding it.

1.

$E D_{R, S, E, F, t}=\sum_{R=1}^{i} \sum_{S=1}^{j} \sum_{E=1}^{k} \sum_{F=1}^{l}\left(\left(\left(\left(\left(\right.\right.\right.\right.\right.$ EDErozenTech $\left._{R, S, E, F, t}\right)+$

EDCBehavMngtChange $\left._{R, S, E, F, t}\right)-$

EDREfficiency $\left._{R, S, E, F, t}\right)-\left(\right.$ EDRedfuslSwitch $_{E, F, t}-$

EDIncFuelSwitch $\left.\left._{E, F, t}\right)\right)-$ EDRedReuse $\left._{R, E, S, F, t}\right)-$

EDRedOnsiteGen Use $e_{R, E, F, t}$ )

The models use a hybrid approach where end-use consumptions, driven by the socio-economic drivers and with a base year technology mix, are estimated first using an energy intensity approach. Then, using a perfect foresight back-casting approach, yearly uptake of each transition option, endogenously modelled with a S-curve, is applied to estimate change in end-use fuel consumption relative to base year levels. All technology 


\section{Offprint provided courtesy of www.icevirtuallibrary.com Author copy for personal use, not for distribution}

assumptions (e.g. efficiency) as well as the final desired level of transition in each option are exogenous to the models. The full modelling methodology is set out in Baruah et al. (2014).

In transport, a set of elasticity-based simulation sub-models forecast the impact on future consumption and capacity utilisation of factors including population, gross value added (GVA) per capita, travel cost and travel speed. An example is given by Equation 2, which shows the intrazonal road traffic model. Transport energy use is derived from the transport services demand, using scenario-specific vehicle fuel efficiency levels from the UK transport carbon model (Brand, 2010). Annual road vehicle fuel mix and the extent of rail electrification are specified prior to simulation, along with a range of other technological and policy options such as vehicle fuel efficiency and congestion and carbon-based tolling (Blainey et al., 2012).

$$
{ }^{2 .}\left(\frac{V k m_{i t+1}}{V k m_{i t}}\right)=\left(\frac{P T r_{P t+1}}{P_{i t}}\right)^{\eta_{p}}\left(\frac{I_{i t+1}}{I_{i t}}\right)\left(\frac{S_{i t+1}}{S_{i t}}\right)^{\eta_{s}}\left(\frac{C_{t+1}}{C_{t}}\right)^{\eta_{c}}
$$

In the electricity peak load model, national level peak load is estimated by summing up individual impact components as in Equation 3.

3.

$$
\begin{aligned}
\text { ElecP }_{t} & =\text { RefPL }_{t}+\text { ElecTransportP }_{t} \\
& + \text { ElecHeatPL }_{t}-\text { DemandResponse }_{t}
\end{aligned}
$$

Reference peak load ( $\operatorname{RefPL})$ is estimated using average annual hourly demand, a flatness measure of peak load profile and a historical relationship between peak load and annual sectoral energy consumption (Dukes, 2013; ECUK, 2013). Transport electrification impact (ElecTransportPL) estimation requires smart meter uptake level, average battery and charger specification, relevant driving ranges and total numbers of BEV/PHEV vehicles charging from the grid (grid-to-vehicle, G2V) and discharging to the grid (vehicle-to-grid, V2G) during peak hours (IEA, 2011; Kempton, 2005). Heat electrification impact (ElecHeatPL) is modelled based on historical differences between average and peak half-hourly gas loads (National Grid, 2013a). Gas peak load is harder to predict (National Grid, 2013b) and a method similar to electricity RefPL estimation, based on historical gas demand and average annual daily gas load (ECUK, 2013), is used. The relationship is assumed to hold good into the future.

Energy supply analysis is carried out by CGEN+, an optimisation model for combined gas and electricity network expansion planning (Chaudry et al., 2008, 2014). This simultaneously minimises the costs for gas and electricity infrastructure expansion and operation, subject to constraints in gas and electricity networks (Equation 4).

4.
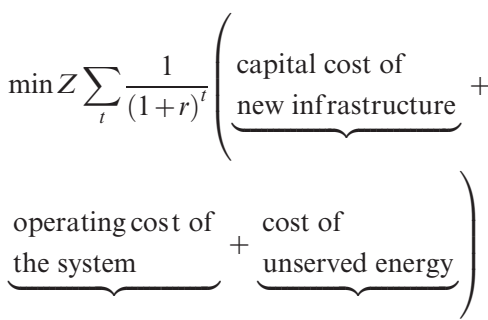

A power generation expansion module determines the optimal type, capacity, location and time that generating plants need to be built given costs for these supply options and required capacity margins. Network expansion is implemented by adding new assets such as pipes, compressors, and storage facilities to the high pressure gas transmission network and increasing transmission circuit capacity in the high-voltage electricity transmission network. New infrastructure expansion, optimal investment/operational costs and emissions are endogenous to the model, whereas sectoral energy consumption, infrastructure attributes (e.g. cost, efficiency) and imposed constraints (e.g. wind capacity in a year) are major exogenous inputs.

\subsection{Input data}

Table 1 shows the socio-economic growth projections investigated in this study. Sub-sectoral GVA and gross domestic product (GDP) projections are produced by Cambridge Econometrics' MDM-E3 model (Cambridge Econometrics, 2013) using projections of energy price, regional demography and world GDP growth that affects UK international trade. Demographic projections use interdependent fertility (birth

\begin{tabular}{llll}
\hline $\begin{array}{l}\text { Socio-economic } \\
\text { growth level }\end{array}$ & $\begin{array}{l}\text { Energy price in 2050 } \\
\text { (Oil: \$/bbl; Gas: p/therm; Coal: } £ / t)\end{array}$ & Demography in 2050: million & GDP in 2050: $£ 2009$ \\
\hline D (High) & Low (Oil: 204; Gas: 104; Coal: 126) & High (Population: 97; Households: 53) & High (£4.1 trillion) \\
A (Central) & Central (Oil: 245; Gas: 183; Coal: 199) & Central (Population: 79; Households: 40) & Central (f3.0 trillion) \\
F (Low) & High (Oil: 496; Gas: 263; Coal: 313) & Low (Population: 66; Households: 32) & Low (f2.7 trillion)
\end{tabular}

Table 1. Socio-economic growth projections investigated in this study 
rate), mortality (death rate) and migration rates (Zuo et al., 2013). Energy price projections are taken from the UK Office of National Statistics (DECC, 2012). More details on these projections are available in Tran et al. (2014).

Residential, services and industry sector base year consumptions are obtained/derived from ECUK (2013). Potential uptake levels of transition options and relevant assumptions are sourced from a wide range of existing studies and expert inputs (Baruah et al., 2014). Base year space heating consumptions are weather corrected prior to simulation. Base year transport data come from a range of sources including the Department for Transport's annual average daily flow data for road traffic, and electronic timetable data for rail traffic.

Base year (year 2010) GB gas and electricity infrastructure capacities are taken from National Grid (2013c, 2013d). Electricity generation technology costs are from MottMacdonald (2010).

\subsection{Scenarios and assumptions}

Two scenarios, electrification of heat and transport (EHT) and a reference minimum policy intervention (MPI), are investigated. The MPI scenario assumes no significant strengthening of UK energy policies to meet climate mitigation goals. Scenario narratives (available in Baruah et al., 2014), prepared with project stakeholders, guide the parameterisation of options and their uptakes in the models. Like similar exercises, these scenarios are arguably simplistic, but the intention is to highlight the implications of an electricity centric transition and assess energy consumption uncertainties from different socio-economic growth patterns.

With the above aim, uptake of all demand-side options except fuel switching is kept at similar levels in both scenarios. Fuel switching in the residential and service sectors occurs in space and water heating where gas-based systems (mainly boilers) are responsible for $80 \%$ and $71 \%$ of respective consumptions. Fuel switching in industry occurs in space heating and low temperature processes that have $14 \%$ and $28 \%$ share of annual industry sector consumption, respectively. Gas-based systems are responsible for $34-57 \%$ of consumption in these end uses (ECUK, 2013).

Table 2 outlines assumed uptake values of major transition options by 2050 in the two investigated scenarios. Both scenarios envision a $5 \%$ improvement in average building fabric performance by 2050 with no other major efficiency and conservation measures. Solar PV uptake is linked to population (one of the proxies for dwelling numbers) and is modest at $43 \mathrm{Wp}$ per person $(\sim 60 \%$ more than base year) in residential and services sectors. By 2050 , only $6 \%$ of hot water energy consumption is met by solar thermal systems. The transport sector in the MPI scenario sees no additional infrastructure built, and no change in vehicle fuel mix and efficiency. No further rail electrification occurs beyond already committed schemes. In energy supply, no particular generation technology is imposed in the MPI scenario. The emission targets in 2050 and renewable target at 2020 are not enforced. The optimal generation mix and network infrastructure expansion is based on cost minimisation and subject to limitation of resources and meeting demand.

In contrast, the EHT scenario envisions large-scale electrification of heating end uses and transport services aided by smart grids. Full smart meter penetration is assumed by 2020 . Ambitious heat pump uptake takes place from the current (in 2012) low penetration of $\sim 20000$ installations $(\sim 17000$ in the residential sector) (CCC, 2013). Heat pumps and electric resistive heating (only heat pumps shown in Table 2) replace $80-85 \%$ and $60-75 \%$ of space and water heating gas (boiler) consumption in the residential and services sectors, respectively. This is in line with CCC's vision of heat pump uptake in $\sim 80 \%$ of all properties by 2050 to meet carbon targets (CCC, 2013). Household gas cooking appliances are replaced with efficient electric ovens and hobs. In industry, heat pumps reach full potential, replacing $15 \%$ and $40 \%$ of gas consumptions in low temperature process heat and space heating, respectively. The iron and steel sector sees share of electric arc furnaces reaching an assumed potential of $80 \%$ from the current $25 \%$ (ISSB, 2012). The transport sector sees moderate vehicle fuel efficiency improvements in all modes, with high uptake of electric vehicles and rapid electrification of the rail network. In 2012, UK market shares for hybrids, plug-in hybrids (PHEV) and battery electric vehicles (BEV) were about $1 \cdot 2 \%, 0 \cdot 1 \%$ and $0 \cdot 06 \%$, respectively (Kay et al., 2013). However, studies have indicated ambitious future uptake ranges for PHEV and BEV by 2050 of $24-50 \%$ and $10-70 \%$, respectively (Hill et al., 2010; Skinner et al., 2010), with large-scale uptake taking off between 2020 and 2030. The EHT scenario assumes a share of roughly $50 \%$ BEVs and $30 \%$ PHEVs in cars by 2050 . This translates to $\sim 26$ million BEV and PHEV cars plying the streets of GB by 2050. Of these vehicles, $20 \%$ are assumed to be charging from the grid $(\mathrm{G} 2 \mathrm{~V})$ and $10 \%$ contributing to peak load response (V2G) during peak hours. Only cars are assumed to be connected to the grid for $\mathrm{G} 2 \mathrm{~V}$ and $\mathrm{V} 2 \mathrm{G}$ purposes during peak hours. Heat pumps (and electric resistive heating) are assumed to meet peak hour heating services demand without using backup systems. It is assumed that current issues with infrastructure (e.g. charging stations), supply chain and other consumer-side uptake barriers (e.g. high capital costs, public acceptance, etc.) are addressed for heat pumps and electric vehicles.

Energy supply-side implications are investigated with a progressively increasing carbon price floor in the MPI scenario. Two contrasting electricity supply mix scenarios are investigated to meet annual energy consumption and peak load in the EHT scenario. A nuclear-centric EHT-nuclear scenario sees successful investments in existing coastal nuclear sites prior to 2020. Growth 
Efficiency and electrification in residential, services and industry sectors

Energy conservation: internal temperature change: ${ }^{\circ} \mathrm{C}$ None Building fabric performance: \% improvement in

Residential and services: 5

average leakage rate of building stock

Lighting efficiency: efficiency/stock change achieved:

$\%$ of savings/change potential

Appliance efficiency achieved: \% of savings potential

Onsite solar thermal installation:

$\%$ of water heating energy consumption met Heating demand met by recovered heat in specified

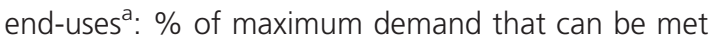
Heating fuel (technology) replaced by alternative technologies in specified end-uses ${ }^{a}$ : total \% replacement range of incumbent

fuel consumption

Heating fuel demand replaced with electric heat pumps in specified end-uses ${ }^{a}$ : \% replacement of gas/electric/oil/solid fuel consumption
Share of electric arc furnace in iron and steel sector Relative ground source heat pump installations in residential and services sectors: \% (ground source + air source heat pumps $=100 \%$ )

Onsite solar PV installation [Watt-peak per person]

Efficiency and electrification in transport sector Road transport fuel efficiency improvement: \% in ICE/BEV/PHEV/hybrid/hydrogen fuel cell vehicle (ICE: internal combustion engine)

Rail, air and sea transport fuel efficiency improvement in: \%

Road transport electrification rate:

$\%$ of BEV/PHEV/hybrid/hydrogen fuel cell vehicle

Rail electrification rate: $\mathrm{km}$ per year

Number of EV/PHEV cars: million

Smart meter uptake and V2G/G2V

Share of end-users connected to grid through smart meters

BEV/PHEV cars connected to the grid for G2V/N2G

during peak hours: ${ }^{\mathrm{b}}$

Electricity supply

Nuclear (2020/2030/2040/2050) [GW]
Residential and services: 10 Industry: 20

Residential and services: 8-10

Residential and services : 6 Industry: 0

Services: 10

Industry: 20

Residential: 9-13

Services: $7-10$

Industry: 9-12

Residential: [3/3/3/3]

Services: [3/3/3/3]

Industry: [3/3/3/3] Industry: 20

Same as MPI

Same as MPI

Same as MPI

Same as MPI

Same as MPI

Same as MPI

Residential: 86-91

Services: 71-83

Industry: 21-49

Residential: [80/80/80/80]

Services: [65/75/60/60]

Industry: low temp. process:

[15/15/15/-];

space heating : [40/40/40/-]

80

50

Same as MPI

Cars: $[0 / 0 / 0 / 0 / 0]$

LGV: $[0 / 0 / 0 / 0 / 0]$

$\mathrm{HGV}:[0 / 0 / 0 / 0 / 0]$

PSV: [0/0/0/0/0]

Rail: 0 Air: 0

Sea: 0

Cars: $[0 / 0 / 0 / 0]$

LGV: [0/0/0/0]

HGV: $[0 / 0 / 0 / 0]$

PSV: [0/0/0/0]

None beyond existing projects 0

Cars: [18/23/27/18/29]

LGV: [19/11/18/18/0]

HGV: [19/0/0/0/25]

PSV: [18/9/24/16/22]

Rail-electric: 58; Rail-diesel: 42

Air: 30

Sea: 35

Cars: [50/30/10/0]

LGV: [50/30/10/0]

HGV: [40/0/40/0]

PSV: [40/30/10/0]

300

26

Same as MPI

G2V: 20/N2G: 10

EHT-nuclear: [13/30/60/90]

Table 2. Uptake of major transition options by 2050 in the two investigated scenarios (continued on next page) 
EHT-offshore:

(2020/2030/2040/2050) [GW]

Wave: $[0 / 0 / 10 / 20]$

${ }^{a}$ Water and space heating in residential and services sectors; low temperature process and space heating in industry

${ }^{\mathrm{b}}$ Availability of G2V and V2G is constrained by penetration of smart meters

Table 2. Continued

continues thereafter with installation of new generation IV nuclear technologies (after 2030). In the EHT-offshore scenario, early and rapid investment in offshore wind, primarily in the North Sea, is envisioned. This is followed by investments in wave and tidal flow after 2030, mainly in the Atlantic. Total yearly capacities in both scenarios are from level 3 of the Department of Energy and Climate Change's 2050 Pathway (DECC, 2010).

\section{Results}

All results below are for central socio-economic growth projections (level 'A' in Table 1), except for energy consumption sensitivity analysis (Section 3.1.3) that uses all three socioeconomic growth projections.

\subsection{Energy consumption implications}

\subsubsection{Electricity, gas and total sectoral energy consumption}

In the EHT scenario, annual GB electricity consumption increases by $35 \%$ in 2050 (compared to reference), which is about 14 times the UK's electricity imports in 2012 (12 TWh). The residential sector sees the largest increase in $2050(35 \%)$

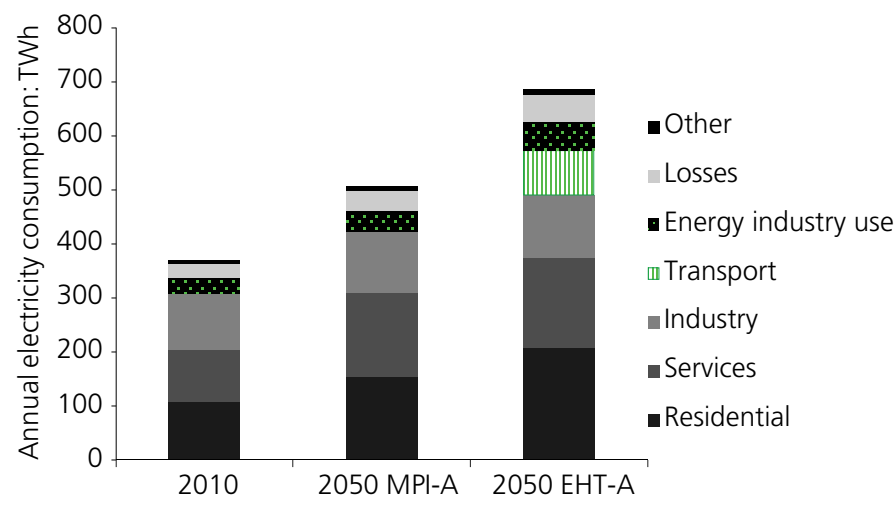

(a) compared to the reference scenario. The transport sector's share of electricity consumption increases from $0.39 \%$ in 2010 to $12 \%(\sim 81 \mathrm{TWh})$ in 2050 . In 2050 , annual electricity consumption in the reference and EHT scenarios is $36 \%$ and $85 \%$ above base year consumption, respectively.

In contrast, ambitious electrification (along with minimal combined heat and power, biomass boilers, etc.) in heating end uses brings down annual sectoral gas consumption in the EHT scenario to $63 \%$ below the reference scenario in 2050 (Figure 2). Gas consumption decreases dramatically in the residential sector $(84 \%)$ followed by the services $(64 \%)$ and industry $(12 \%)$ sectors. On the other hand, continuing with a largely incumbent technology mix, the reference scenario sees an $18 \%$ increase in annual gas consumption above base year level. Consumption from gas-based electricity generation and other relevant sources (e.g. supply losses) are not included in Figure 2. These are taken into account in energy supply analysis.

The EHT scenario could reduce total sectoral energy consumption (excluding the transport sector) below base year level and

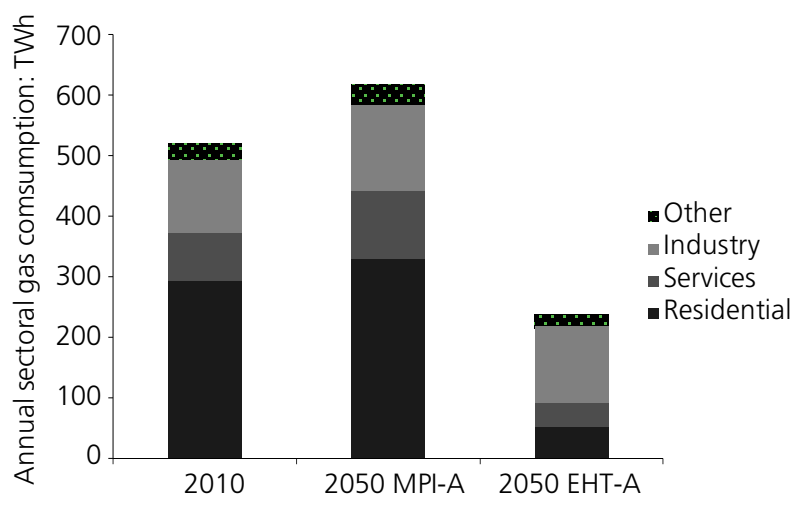

(b)

Figure 2. Annual (a) electricity and (b) gas consumption in MPI (reference) and EHT scenarios with central socio-economic growth 
by $\sim 28 \%$ below the reference scenario. The largest reduction is achieved in the residential sector $(\sim 47 \%)$, followed by services $(\sim 24 \%)$ and industry $(\sim 5 \%)$. Water and space heating energy consumption decreases by $61 \%$ and $52 \%$, respectively, primarily by switching to efficient heat pumps.

\subsubsection{Peak electricity and gas loads}

Figure 3(a) shows electricity peak load evolution in the MPI and EHT scenarios. Using assumptions set out in section 2.3, peak load increases by $93 \%$ (above reference level) with a 35\% increase in annual electricity consumption in the EHT scenario. Peak hour heat pump (and electric resistive heating) use and G2V/V2G are responsible for $23 \%$ and $16 \%$ of total peak load respectively in 2050 (Figure 3(a)). Heat and transport electrification's shares of annual electricity consumption are $12 \%$ and $9 \%$, respectively.

Gas peak load evolution in both scenarios (Figure 3(b)) follows similar paths to total gas consumption evolution. With rapid replacement of gas-based heating systems, peak gas load and annual gas consumption decrease $73 \%$ and $62 \%$ below reference scenario level in the EHT scenario by 2050 .

\subsubsection{Energy consumption uncertainty from differing socio-economic growth}

This analysis demonstrates that significant energy consumption uncertainties can arise from uncertainties in socio-economic growth projections. As seen in Figure 4, within the two scenarios, GB electricity consumption can range from $\sim 400 \mathrm{TWh}$ to more than 900 TWh by 2050 - the bound is $\sim 1.4$ times UK's total electricity supply in 2012 ( $\sim 375 \mathrm{TWh})$. Upper (EHT-D) and lower (MPI-F) estimates lie $86 \%$ above and 19\% below reference consumption (MPI-A). Intra-scenario variations in 2050 lie
$17-19 \%$ below or $37-45 \%$ above respective estimates (MPI-A and EHT-A).

Similarly, gas consumption sensitivity shows $45 \%$ higher (MPID) and $71 \%$ lower (EHT-F) values than the MPI-A scenario in 2050. The difference is $\sim 1 \cdot 3$ times the base year gas demand. Intra-scenario consumption in 2050 is found to be $20-24 \%$ below and $45-68 \%$ above respective central estimates.

\subsection{Energy supply implication}

The generation capacity mix for the two scenarios is shown in Figure 5. In the MPI scenario, imposing a carbon price floor ( $£ 16 / \mathrm{t}$ in $2014, £ 30 / \mathrm{t}$ in 2020 and $£ 70 / \mathrm{t}$ in 2030 and beyond) makes coal power plants more expensive to run, and less economic to build compared to combined cycle gas turbine (CCGT) and nuclear plants. CCGT capacity increases from under $30 \mathrm{GW}$ in 2010 to $73.5 \mathrm{GW}$ by 2050 and accounts for $\sim 70 \%$ of total capacity. New nuclear plants become economically attractive from 2030 onwards as the carbon price floor increases to $£ 70 /$ t.

In the EHT scenario, much more capacity (than MPI) is required reflecting the significantly higher annual energy consumption and peak load. The variable output of wind turbines means the generation capacity required in an EHT-offshore scenario is even higher $(>300 \mathrm{GW})$ than in the MPI or EHT-nuclear scenarios.

In the MPI scenario, CCGT power plants on average maintain a capacity factor of almost $50 \%$ throughout the period from 2010 to 2050. Owing to gas price variations in 2050 CCGT capacity factors during summer/intermediate periods are much higher than the annual average value. The capacity factor of CCGT plants drops significantly in the EHT scenario (less than

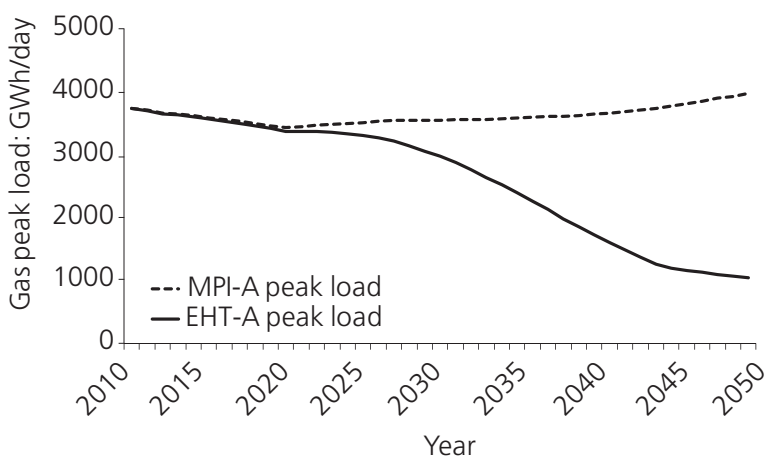

(b)

Figure 3. Evolution of (a) peak electricity and (b) peak gas load in MPI (reference) and EHT scenarios with central socio-economic growth 


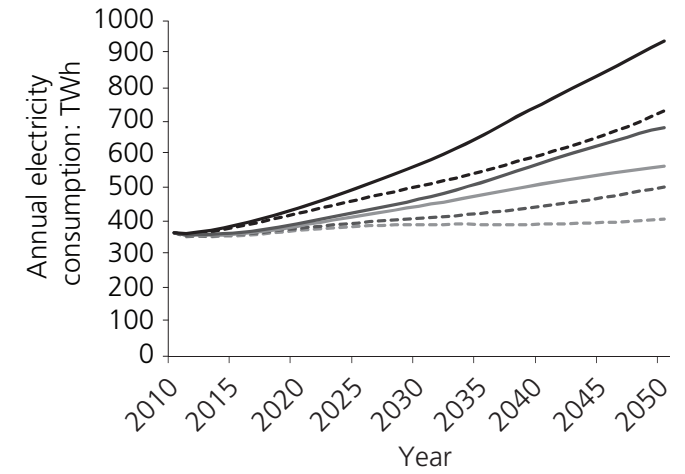

(a)

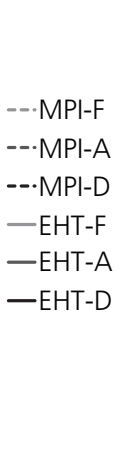

$-\cdot M P I-A$

$\cdots$ MPI-D

-EHT-A

EHT-D

Figure 4. Evolution of (a) annual electricity and (b) annual gas consumption in MPI (reference) and EHT scenarios with low (F), central (A) and high (D) socio-economic growths

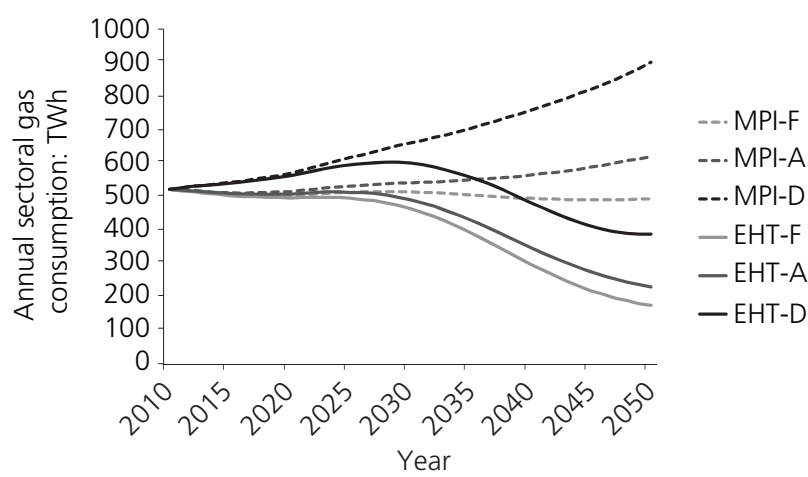

(b)
$10 \%$ ) mainly owing to the role of CCGT plants to back up variable and inflexible generation from wind and nuclear. This highlights the importance of incentives such as capacity payments to encourage such CCGT plants to be built.

The total discounted cumulative costs in 2010-2059 (with a 10 -year planning time step) and the carbon dioxide equivalent emission intensity in 2050 from electricity generation are shown in Figure 6. In the MPI scenario the cost of gas network operation, consisting of the cost of energy consumed by gas compressors and gas purchase from suppliers (including for gas-fired generators), has the largest share of total costs. Results for the EHT scenario indicate that electricity system capacity expansion and operation account for the bulk of the costs to 2050 as the overall energy system is electrified. Gas transmission network capital expenditure is relatively small

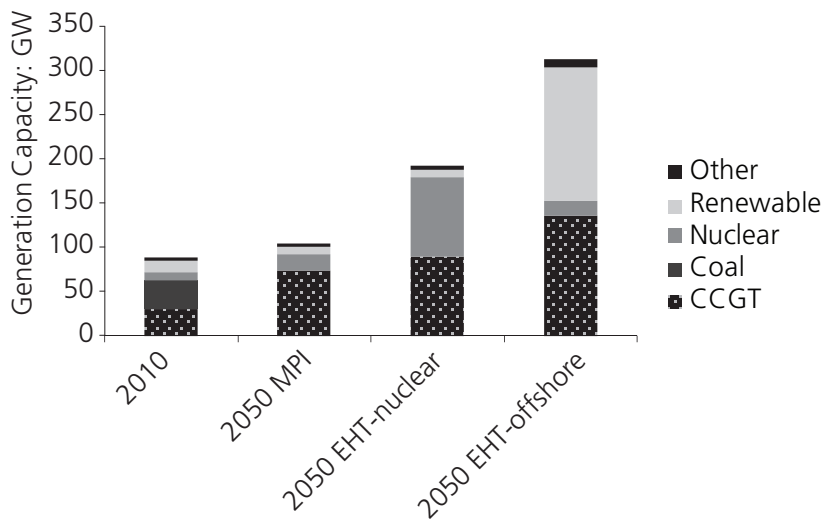

Figure 5. Electricity generation capacity mix in MPI (reference) and EHT scenarios with central socio-economic growth compared to other cost components, mainly owing to a decrease (in the EHT strategies) or very slight increase (in the MPI strategy) in total gas consumption. This means there is no real need to build large-scale gas infrastructure, and only maintenance is needed.

Figure 6 does not include demand-side costs (such as from heat pump installation, efficiency improvement, BEV/PHEV charging infrastructure, smart meters, etc.) and costs incurred in the gas and electricity distribution networks.

In MPI, the carbon dioxide equivalent emission intensity from the electricity system falls from just above $500 \mathrm{~g} / \mathrm{kWh}$ in 2010 to $224 \mathrm{~g} / \mathrm{kWh}$ in 2050 . This is mainly attributable to replacing coal power plants with new CCGT and nuclear plants. For EHT variants the carbon dioxide emission intensity falls significantly to $31 \mathrm{~g} / \mathrm{kWh}$ for EHT-nuclear and $63 \mathrm{~g} / \mathrm{kWh}$ for EHT-offshore, by 2050 .

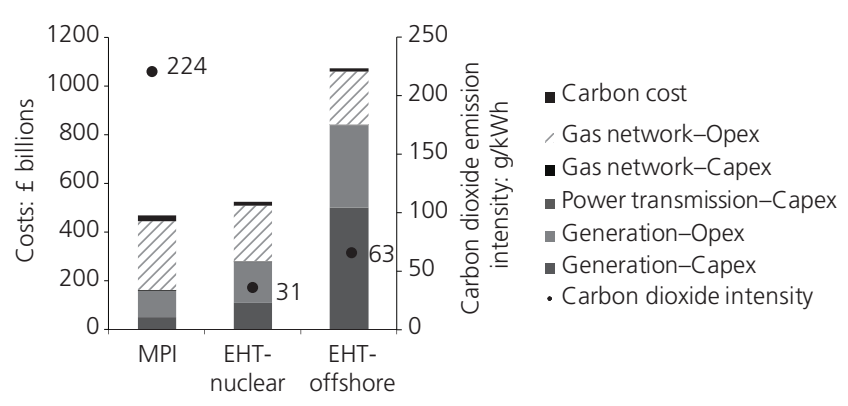

Figure 6. Total discounted costs and 2050 carbon dioxide equivalent emission intensity in scenarios with central socioeconomic growth 


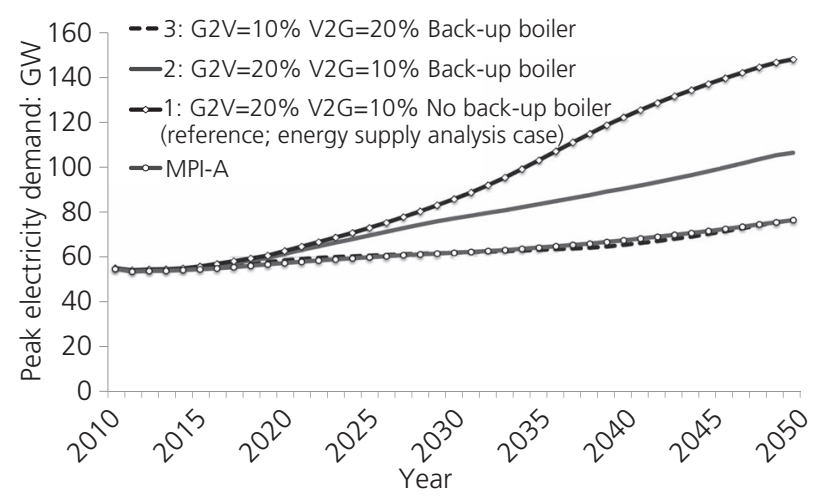

Figure 7. Electricity peak load sensitivity with different levels of G2V, V2G and heat pump back-up system availability (EHT scenario with central socio-economic growth)

\section{Discussion}

With MPI, GB will be using substantial quantities of fossil fuels including natural gas for heating services and oil for transport. With an electrification pathway total annual energy consumption can be reduced along with significant decreases in consumption and import dependency of natural gas and oil. However, the final level of gas dependency will be determined by the electricity generation mix and demand management regime pursued. In a high offshore scenario, there continues to be dependence on gas-based back-up generators for maintaining grid flexibility. Given that overcoming the gas 'lock-in' is essential to deliver carbon targets, some combination of demand-side management, energy storage and/or much stronger connection to a future European super-grid will have to be in place if the UK is to minimise the need for large back-up capacity in an EHT-offshore scenario.

The simple sensitivity analysis presented in Figure 7 illustrates such peak load management potential under a smart grid enabled electrification scenario. As seen in case 2, heat pumps with non-electric back-up systems (e.g. hybrid heat pumps) could potentially reduce the electricity peak load by about a third (over base case 1). Enabling 10\% higher system-wide V2G and equally lower G2V flow during peak hours could further lower peak load to the reference scenario level. With appropriate business models, electric vehicles can also provide ancillary services, such as frequency control and spinning reserves, closer to the load, minimising relevant supply infrastructure needs. In mitigating diurnal demand peaks, heat storage within buildings (e.g. using hot water tanks, phase change materials) can provide similar advantages to electric vehicles, but seasonal impacts are unavoidable without largescale heat storage. Technological innovation, investment in
$\mathrm{R} \& \mathrm{D}$, demonstration projects and early deployment would be crucial to ensure cost-effective and timely uptakes of these options to avoid undesirable 'lock ins' (EC, 2011; Think, 2011; Unruh, 2000). The UK's electricity market reform (DECC, 2013b), where storage and demand-side response measures are eligible to participate in a 'capacity market', is a positive step in this direction. However, user participation driven by an innovative power market that can deal with millions of demand/supply nodes is another area for technological and policy innovation to realise the demand-side management benefits from electrification.

It should be noted that ambitious efficiency and conservation measures in buildings and appliances can further reduce both total annual energy consumption and peak load, minimising supply-side infrastructure needs (Eyre, 2011). Also, for heat pumps to operate close to optimal efficiency, building thermal efficiency has to be high. This study used conservative heat pump efficiencies, minimal building envelope efficiency improvement and no conservation measures to highlight the potential implications from high electrification.

As the present results show, there is significant uncertainty in supply-side infrastructure costs from meeting high electricity consumption with competing and plausible supply-side portfolios, especially when the available levels of demand-side management and other flexibility measures such as interconnection are not clear.

Apart from the potentially high capacity needs, electrification can increase stranded asset and decommissioning pressures on the vast existing gas and oil infrastructure in the UK. Considerable reductions in distribution network level gas consumption would impact on the UK's $\sim 285000 \mathrm{~km}$ of dense gas distribution and $\sim 7600 \mathrm{~km}$ of transmission pipelines, with major effects on the gas industry and its employment. Greater use of biogas through the existing infrastructure could mitigate this, although the extent to which biogas can be sourced in a densely populated country like the UK requires further investigation. In contrast to heat, transport decarbonisation has limited alternatives beyond electrification in the UK context. Although biofuel is an alternative, a biofuel-centric transport system would mean large imports with supply security concerns. Additionally, concerns over the carbon neutrality and land-use impacts of the current generation of biofuels need to be taken into account in such a transition. Additionally, it is likely that air transport will be given priority for biofuel use in such a transition. Extensive transport electrification and moving away from oil also has to take into account the impacts on the existing oil industry with its pipeline network, refineries and approximately 8500 petrol filling stations. Future studies would need to consider these concerns and include relevant costs for a thorough assessment of an electrification pathway. 
On the user side, electrification would incur considerable costs (not estimated here) from heat pump installation and electric vehicle purchase. Both of these currently have higher upfront (but lower operational) costs than incumbent systems, meaning such large-scale transitions would require government intervention to provide both suitable incentives and an adequate supply chain.

Management of a highly distributed electricity load would also mean increased bi-directional flows (from vehicle to grid and exported electricity from onsite generation) and greater power transmission between geographically distant generators and major consumption regions. This would require a smarter grid and reinforcement of both transmission and distribution infrastructure.

The results show that transmission infrastructure costs are likely to be significantly lower than generation-related costs. Distribution costs are not estimated in the study. However, as Pudjianto et al. (2013) estimated, cumulative electricity network reinforcement costs during 2010-2050 could be $\sim £ 35$ billion for a peak load of $\sim 3$ times the base year level (in this case 2.7 times) this is less than $\sim 3 \%$ of capacity and transmission costs in the EHT-offshore scenario. This highlights that carefully planned transmission and distribution investments can be potential 'noregret' options for enabling greater microgeneration uptake and exploitation of geographically distributed renewable resources. In the supply scenarios, EHT-nuclear scenario costs are found to be about half of EHT-offshore scenario costs. However, this finding should be treated with caution given the long lead time and high cost uncertainty (often costing several times of the original estimate) of nuclear projects (Greenacre, 2012; Grubler, 2010).

Finally, as the consumption sensitivity analysis demonstrates uncertainties in socio-economic growth projections can exacerbate the impact on consumption in a single carrier pathway such as electrification. This can impact on both the new (electricity) and incumbent (gas and oil) energy carriers, with associated infrastructure implications. This highlights the importance of testing a diverse set of scenarios in order to identify robust and resilient strategy options to decouple energy consumption and socio-economic growth. Finding such a pathway that minimises future energy price volatility (and increases economic competitiveness) is key to solving the trilemma of energy security, affordability and greenhouse gas reductions.

\section{Conclusion}

This study has conducted a scenario analysis of a high electrification future in GB using a suite of explicit energy demand and supply models. The analysis confirms that a high heat and transport electrification pathway would reduce overall annual energy consumption while considerably increasing both annual electricity consumption and peak load, with an increase of $93 \%$ in electricity consumption and $35 \%$ in electricity peak load compared to a reference scenario. However, with greater use of demand-side management measures available with electrification, such as V2G, it would be possible to arrest or even reduce peak load below reference scenario levels. Without peak demand management, electricity generation capacity and transmission costs in a high electrification pathway can vary widely depending on the supply mix pursued (a range of $\sim £ 450-1100$ billion was found for two highly plausible supply mixes). Utilising domestic offshore wind resources to meet the high electricity demand would mean high infrastructure costs and continued dependence on large gas-fired back-up capacity.

Electrification can reduce dependence on imported gas and oil while facilitating connection of a large part of the UK energy system to a future European super-grid and energy market. Nonetheless, the required level of uptake of heat pumps and electric vehicles as well as dramatic reductions in gas and oil consumption seen in these scenarios indicate that there are major implications both for consumers and the existing national gas and oil infrastructure/industry in an electrification scenario. These implications could be exacerbated in the longer term by energy consumption uncertainties linked to socio-economic growth, which the sensitivity analysis found to be significant.

\section{Acknowledgement}

The research described in this paper was funded by the UK Engineering and Physical Sciences Research Council under programme grant $\mathrm{EP} / \mathrm{I} 01344 \mathrm{X} / 1$ to the UK Infrastructure Transitions Research Consortium.

\section{REFERENCES}

Barton J, Huang S, Infield D et al. (2013) The evolution of electricity demand and the role for demand side participation, in buildings and transport. Energy Policy 52: 85-102.

Baruah P, Chaudry M, Qadrdan M, Eyre N and Jenkins N (2014) Energy Supply and Demand Planning. In Infrastructure for the 21st Century: Systems of Systems Methodology for Analysing Society's Lifelines in an Uncertain Future (Hall J, Nicholls R, Tran M, Hickford A and Otto A (eds)). Cambridge University Press, Cambridge, UK.

Blainey SP, Preston JM and McLeod F (2012) A long term capacity and demand assessment model for the UK transport system. In Proceedings European Transport Conference, Glasgow, UK. Association of European Transport, London, UK. See https://abstracts.aetransport. org/paper/index/id/3987/confid/18 (accessed 11/08/2014).

Brand C (2010) UK Transport Carbon Model: Reference Guide. Working Paper. Environmental Change Institute, University of Oxford, Oxford, UK. 


\section{Offprint provided courtesy of www.icevirtuallibrary.com Author copy for personal use, not for distribution}

Cambridge Econometrics (2013) Brief Description of MDM-E3, Version 1.0. Cambridge Econometrics, Cambridge, UK.

CCC (Committee on Climate Change) (2013) Fourth Carbon Budget Review - Technical Report. UK Committee on Climate Change, London, UK.

Chaudry M, Jenkins N and Strbac G (2008) Multi-time period combined gas and electricity network optimization. Electric Power Systems Research 78(7): 1265-1279.

Chaudry M, Jenkins N, Qadrdan M and Wu J (2014) Combined gas and electricity network expansion planning. Applied Energy 113: 1171-1187.

DECC (Department of Energy and Climate Change) (2010) 2050 Pathway Analysis Report. HM Government, London, UK.

DECC (2012) Updated Energy and Emissions Projections 2012. DECC, London, UK.

DECC (2013a) Electricity Market Reform: Capacity Market Detailed Design Proposals. DECC, London, UK.

DECC (2013b) The Future of Heating: Meeting the Challenge. UK DECC, London, UK.

Dukes (2013) Digest of UK Energy Statistics (DUKES). See https://www.gov.uk/government/collections/digest-of-ukenergy-statistics-dukes (accessed 01/07/2013).

Dyke K, Schofield N and Barnes M (2010) The impact of transport electrification on electrical networks. IEEE Transactions on Industrial Electronics 57(12): 3917-3926.

EC (2011) Energy Roadmap 2050: Impact Assessment and Scenario Analysis. European Commission, Brussels, Belgium.

ECUK (2013) Energy Consumption in the UK (ECUK). See https://www.gov.uk/government/collections/energyconsumption-in-the-uk (accessed 10/01/2013).

Eurelectric (2011) Power Choices: Pathways to Carbon-Neutral Electricity in Europe by 2050. Eurelectric, Brussels, Belgium.

Eyre N (2011) Efficiency, Demand Reduction or Electrification? Energy Efficiency First: The Foundation of a Low Carbon Society. European Council for an Energy Efficient Economy Summer Study, Presqu'ile de Giens, France.

Fernández LP, San Román TG, Cossent, R, Domingo CM and Frías $P$ (2011) Assessment of the impact of plug-in electric vehicles on distribution networks. IEEE Transactions on Power Systems 26(1): 206-213.

Frontier Economics (2013) Pathways to High Penetration of Heat Pumps (Report prepared for the Committee on Climate Change by Frontier Economics and Element Energy). Frontier Economics, London, UK.

Greenacre P (2012) UKERC Technology and Policy Assessment Cost Methodologies Project: Nuclear Case Study (Working Paper). UK Energy Research Centre, London, UK.

Grubler A (2010) The costs of the French nuclear scale-up: A case of negative learning by doing. Energy Policy 38: 5174-5188.

Hall JW, Henriques JJ, Hickford AJ and Nicholls RJ (2013) Systems-of-systems analysis of national infrastructure.
Proceedings of Institution of Civil Engineers - Engineering Sustainability 166(5): 249-257.

Hall JW, Henriques JJ, Hickford A et al. (2014) Assessing the longterm performance of cross-sectoral strategies for national infrastructure. Journal of Infrastructure Systems, American Society for Civil Engineering (ASCE). doi: 10.1061/ (ASCE)IS.1943-555X.0000196.

Hill N, Morris M and Skinner I (2010) EU Transport GHG: Routes to 2050? SULTAN: Development of an Illustrative Scenarios Tool for Assessing Potential Impacts of Measures on EU Transport GHG. AEA, London, UK.

IEA (International Energy Agency) (2011) Impact of Smart Grid Technologies on Peak Load to 2050. IEA, Paris, France.

ISSB (International Steel Statistics Bureau Ltd.) (2012) Annual Statistics. ISSB, London, UK.

Kay D, Hill N and Newman D (2013) Powering Ahead: The Future of Low-carbon Cars and Fuels. UK Petroleum Industry Association and Royal Automobile Club Foundation for Motoring, London, UK.

Kempton W and Tomić J (2005) Vehicle-to-grid power implementation: From stabilizing the grid to supporting large-scale renewable energy. Journal of Power Sources 144(1): 280-294. doi:10.1016/j.jpowsour.2004.12.022

MottMacdonald (2010) UK Electricity Generation Costs Update (June, 2010). DECC, London, UK.

National Grid (2013a) National Grid Operational Data National Grid Seasonal Normal Demands. See http://www2. nationalgrid.com/uk/industry-information/gastransmission-operational-data/ (accessed 01/07/2013).

National Grid (2013b) UK Future Energy Scenarios. National Grid, London, UK.

National Grid (2013c) 2013 Ten Year Gas Statement. National Grid, London, UK.

National Grid (2013d) 2013 Ten Year Electricity Statement. National Grid, London, UK.

Pudjianto D, Djapic P, Aunedi M et al. (2013) Smart control for minimizing distribution network reinforcement cost due to electrification. Energy Policy 52: 76-84.

RAE (Royal Academy of Engineering) (2010) Generating the Future: UK Energy Systems fit for 2050. RAE, London, UK. Richardson DB (2013) Electric vehicles and the electric grid: a review of modeling approaches, impacts and renewable energy integration. Renewable and Sustainable Energy Review 19: 247-254.

Skea J, Ekins P and Winskel M (eds) (2011) Energy 2050: The Transition to a Secure Low Carbon Energy System for the $U K$. Earthscan, London, UK.

Skinner I, van Essen H, Smokers R and Hill N (2010) EU Transport GHG: Routes to 2050? Towards the Decarbonisation of the EU's Transport Sector by 2050. AEA, London, UK.

Think (2011) Transition Towards a Low Carbon Energy System by 2050: What Role for the EU. Think Project, European Union 7th Framework Program, Brussels, Belgium. 
Tran M, Hall J, Hickford A et al. (2014) National infrastructure assessment: Analysis of options for infrastructure provision in Great Britain, Interim Results. Environmental Change Institute, University of Oxford, UK.

Unruh GC (2000) Understanding carbon lock-in. Energy Policy 28(12): $817-830$.
Zuo C, Birkin M and Malleson N (2013) Dynamic microsimulation modeling for national infrastructure demand in an uncertain future. In Proceedings of 12 th International Conference of Geocomputation, Wuhan, China. See http://www.geocomputation.org/2013/papers/29.pdf (accessed 11/08/2014).

\section{WHAT DO YOU THINK?}

To discuss this paper, please email up to 500 words to the editor at journals@ice.org.uk. Your contribution will be forwarded to the author(s) for a reply and, if considered appropriate by the editorial panel, will be published as discussion in a future issue of the journal.

Proceedings journals rely entirely on contributions sent in by civil engineering professionals, academics and students. Papers should be 2000-5000 words long (briefing papers should be 1000-2000 words long), with adequate illustrations and references. You can submit your paper online via www.icevirtuallibrary.com/content/journals, where you will also find detailed author guidelines. 